\title{
A three-tiered approach to investigating patient safety incidents in endoscopy: 4-year experience in a teaching hospital
}

\section{다 (1) $\odot$}

\author{
Authors \\ Philip Berry, Sreelakshmi Kotha, Giovanni Tritto, Sabina DeMartino
}

\author{
Institution \\ Department of Gastroenterology, Guy's and St Thomas' \\ Foundation Trust, London, United Kingdom
}

submitted 4.12.2020

accepted after revision 11.3.2021

\section{Bibliography}

Endosc Int Open 2021; 09: E1188-E1195

DOI 10.1055/a-1479-2556

ISSN 2364-3722

(C) 2021. The Author(s).

This is an open access article published by Thieme under the terms of the Creative Commons Attribution-NonDerivative-NonCommercial License, permitting copying and reproduction so long as the original work is given appropriate credit. Contents may not be used for commercial purposes, or adapted, remixed, transformed or built upon. (https://creativecommons.org/licenses/by-nc-nd/4.0/)

Georg Thieme Verlag KG, Rüdigerstraße 14,

70469 Stuttgart, Germany

\section{Corresponding author}

Sreelakshmi Kotha, Department of Gastroenterology, Guy's and St Thomas' Hospital, Westminster Bridge Rd, Lambeth, London, London SE1 7EH, UK

Fax: +0002071887188

sreelakshmi_kotha@yahoo.com

\section{ABSTRACT}

Background and study aims Patient safety incidents (PSIs) in endoscopy, although infrequent, can lead to signif- icant morbidity or mortality. There is no commonly agreed strategy to investigate PSIs. We describe a three-tiered approach to investigation to facilitate appropriate action, shared learning, and timely disclosure to patients as mandated in the UK health system by the Duty of Candor (DoC). Methods PSIs were identified prospectively over a 3-year, 7-month period in a large teaching hospital. Level of investigation was agreed by a group of three senior clinicians. Levels of investigation comprised: 1 ) rapid desktop review; 2) departmental "mini-root cause analysis" (mini-RCA, developed internally); and 3) hospital-level RCA or mortality review.

Results Of 63006 procedures there were 73 reported cases of significant harm. Eleven resulted in death. Thirty PSIs were related to hepatobiliary endoscopy, 17 to lower gastrointestinal endoscopy, and 26 to upper gastrointestinal endoscopy. Hospital-level RCA was performed in six cases, mini-RCA/mortality review in 14, and 53 were examined by the endoscopy lead. Findings were presented in an endoscopy user group (EUG) meeting. There was learning in relation to informed consent, pre-procedural radiology reviews, pre-procedural treatment, escalation planning, teamwork and communication, preparation of equipment, and recognition of delayed complications. Open and honest communication with patients and relatives was facilitated.

Conclusions The introduction of an endoscopy-tailored investigation tool, the mini-RCA, as part of a three-tiered approach, facilitated investigation, appropriate action, learning, and disclosure after PSIs.

\section{Introduction}

Although the incidence of significant endoscopy-related complications is low ( $\leq 1$ in 1000), all units encounter cases of moderate to severe harm on a regular basis due to the large number of procedures performed. To date, there is no universal agreement on an investigation strategy following patient safety incidents (PSIs) in endoscopy.

Root cause analysis (RCA) is a general tool used to investigate a wide variety of hospital-based PSIs but is not tailored to endoscopic practice. RCA has been criticised for encouraging a focus on error, and in most hospitals, it is reserved for the most severe cases [1]. RCAs are also time- intensive and are not well suited to incidents that arise regularly, or those that can be regarded as expected complications and are better analyzed as trends rather than individually [2]. PSIs that do not meet criteria for RCA (e.g. near misses or no/low harm incidents) may undergo informal local investigation or occasional discussion in clinical meetings. Informal investigations that are not centrally recorded carry the risk that series of near misses or evolving patterns go undetected. Lessons arising from them may not 
be properly disseminated if they occur "below the radar" of a formal internal governance mechanism.

An additional investigation tool in the UK is the Structured Judgement Report (SJR), developed by the Royal College of Physicians to encourage learning from deaths [3]. This is used, by definition, only after a fatal outcome and is designed to highlight strengths and weaknesses in care both before and after surgical procedures (if performed). The SJR is not well suited to endoscopy-related PSI, as deaths are rare and SJRs are designed to focus on several phases of clinical care before and after specific interventions, rather than procedures.

Regulation 20 of the UK's Health and Social Care Act (2014) mandates transparent, honest, and timely disclosure to patients after PSIs causing harm, in a structured process called the Duty of Candor (DoC) [4]. Timely and open discussion about adverse outcomes is crucial to alleviate patient and relative grievance, maintain trust, and prevent ensuing legal challenges. This is another reason why processes following PSIs need to be efficient and reliable.

The UK's Joint Advisory Group on Gastrointestinal Endoscopy (JAG) has developed a tailored approach to analyzing endoscopy PSIs, based on categories defined by the National Reporting and Learning System (NRLS) [5,6]. This allows a structured approach and highlights areas of practice that were found to be the source of error in a large observational study [6].

In our unit, we developed a mid-level investigation tool, the mini-RCA, and evaluated it along with other tools in an analysis of PSIs and outcomes over nearly 4 years.

\section{Methods}

\section{Description of the endoscopy unit}

Guy's \& St Thomas' Endoscopy Department is part of a large teaching hospital in London, UK. Approximately 18,000 endoscopic procedures are performed per year, by medical and surgical endoscopists, trainees, and nurse endoscopists. In addition to routine diagnostic endoscopy and inpatient emergencies, complex therapeutic procedures are carried out, including large colonic polypectomy, esophageal radio frequency ablation (RFA), esophageal and gastric endoscopic submucosal dissection (ESD), endoscopic retrograde cholangiopancreatography (ERCP) and cholangioscopy, endoscopic cystgastrostomy with pancreatic necrosectomy and intragastric balloon (IGB) insertion. Nurse-led preassessment occurs for all patients on the day of the procedure. Furthermore, therapeutic endoscopy patients are reviewed approximately 1 week before the procedure. Complex and higher-risk procedures (e.g. ERCP, ESD) are discussed in appropriate multidisciplinary team (MDT) meetings. A two-stage consent process follows unless clinical urgency precludes a period of patient reflection. The endoscopy training lead maintains a list of endoscopists and procedures for which they are signed off (in the case of trainees) or have specialist training. A team brief is held at the start of each list, and a modified World Health Organization (WHO) checklist is completed before every procedure. Regular audits of quality and safety are performed, and the department has not been identified as an outlier in any of the "Global Rating Scale: metrics. Complication rates in therapeutic endoscopy all fall within nationally agreed thresholds.

\section{Notification and stratification of patient safety incidents}

PSIs were defined in this unit as unexpected events during or clearly related to endoscopy causing harm or resulting in unplanned admission, readmission, or prolonged admission. Near misses were also included if the potential consequences were serious. The grading of harm (into mild, moderate, severe, and death categories) was guided by the NRLS. PSIs were reported by endoscopists and also proactively identified by the endoscopy lead clinician from a 3-month report of all unplanned admissions within 8 days and deaths within 30 days from an endoscopy. PSIs were reported via a hospital-wide electronic portal designed to collect incidents (Datix). Additional sources for PSIs were a "complications" book kept in endoscopy for nurse and endoscopist immediate documentation, formal patient complaints, and occasionally, informal communication from neighboring hospitals or patients themselves.

Following the identification of a PSI, a group of three senior clinicians, including the endoscopy lead, the Gastroenterology Department lead and the clinical lead for patient safety, agreed on the appropriate level of investigation. When members of the safety team were involved in a PSI, the investigation was led by a colleague.

The decision about level of investigation was based not only on the harm grading but also on predictability of the complication, the overall physical status and frailty of the patient, and the anticipated pre-procedural risk. Pre-procedural risk was assessed based on American Society of Anesthesiologists (ASA) performance status, the degree of acute physiological derangement, the level of care required (e.g. critical care vs ambulant), and the proposed procedure. These was assessed qualitatively, in light of the safety team experience. Consequently, an unexpected complication in a fit patient may have triggered a more in-depth investigation than a serious event following a very high-risk procedure in a frail patient. The endoscopists and/or nurses involved in the incident were kept informed and supported throughout the process, to promote a non-judgmental and open culture, which would prioritize learning over blaming.

\section{Development of the mini-RCA investigation tool}

Traditionally, incidents resulting in "severe harm" or "death" were investigated with the standard hospital-level RCA process, while incidents resulting in lesser degrees of harm were examined by the endoscopy lead clinician. The National Patient Safety Framework stipulates a 60-day turnaround time for hospitallevel RCAs. Recognizing that investigation of endoscopy PSIs needed to be better distributed, formalized, and streamlined, we developed a "mini-RCA" tool in October 2016 to be used after significant but recognized complications of the procedure, including perforations, bleeding, sedation-related events, and unexpected deterioration during recovery or on the ward. 


\section{Endoscopy perforation/complication: mini-RCA}

Datix:

Degree of harm:

Clinical summary:

8. Was the duty of candour observed?

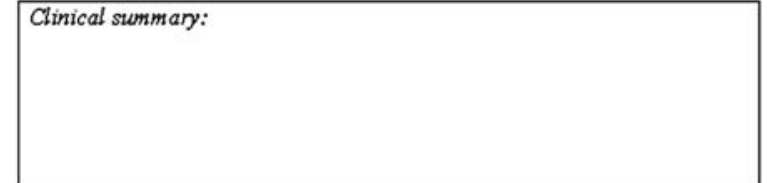

9. Has the patient suffered long term ill-effects?

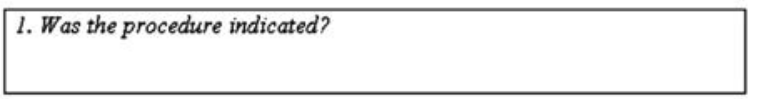

10. Are there wider lessons to learn from this incident?

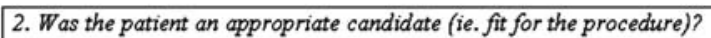

3. Was the consent process followed?

4. Was the endoscopy checklist used?

(person responsible)

Is re-training required?

Is formal RCA required?

Have lessons been disseminated?

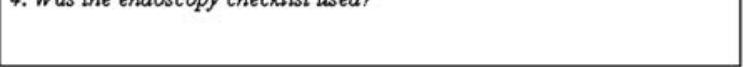

5. Was the endoscopist working within their competency?

\begin{tabular}{|l|}
\hline 6. Are relevant KPIs (Key Performance Indicators) available? \\
\hline
\end{tabular}

Signed:

7. Were the actions taken post-perforation appropriate?

\section{Date of EUG discussion:}

Date of GI governance discussion:

-Fig. 1 Mini-RCA proforma.

Intermediate investigation tools, such as the Concise Incident Analysis Tool (CIA) have been developed [7]. The CIA used a series of "guiding questions" to ensure that the investigation is focused. Example questions include "Were the education, experience, training, and skill level appropriate?" and "Was the information required to make care decisions available and up-to-date (e.g., test results, documentation, patient identification)?"

The mini-RCA comprises guided questions that elicit essential information about patient presentation, endoscopist competence, and key performance indicators (KPIs), completion of the modified WHO checklist, procedural and post-procedural care, and a free-text section in which the investigator can describe any issues and learning opportunities ( $\mathbf{F i g}$. 1). Evidence for the mini-RCA was obtained from patient records and accounts of events from those involved in the procedure, including nurses and endoscopy assistants where appropriate. Sections were also included to confirm that open and transparent communication with the patient and/or relatives had taken place in accordance with the DoC recommendations, that learning was shared with the wider team and recommended changes in practice were implemented. Although unvalidated, the new investigation process was approved by the hospital's central Quality and Patient Safety team. In view of delays identified in investigating previous PSIs and the risk of lost learning opportunities, it was felt appropriate to introduce a focused tool without formal validation. Its similarity to established tools (e. g. CIA) justified this; similar adaptations to endoscopy have been made with validated safety tools, such as the WHO checklist.

An experienced clinician, not involved in the endoscopic procedure, was invited to perform the mini-RCA after agreement that this was the appropriate level of investigation. The departmental lead for patient safety and clinical governance ensured that the investigators were properly trained in the principles of PSI investigation. The endoscopist involved in the incident was asked to provide a short, written account of the events.

Not all fatal outcomes necessarily led to a hospital-level RCA as the decision depended more on the likelihood, the avoidability, the presence of potential error or important learning points for the organization. This parallels processes in other departments, where deaths considered inevitable, or where it is felt 
- Table 1 Causes of mortality

\begin{tabular}{|c|c|c|}
\hline Procedure & Number & Cause of death \\
\hline ERCP & 7 & $\begin{array}{l}2 \times \text { intraprocedural arrest. Frail patients with advanced malignancy. } \\
1 \times \text { post-cholangioscopy in end-stage liver disease } \\
1 \times \text { post-cholangioscopy due to multidrug-resistant cholangitis } \\
1 \times \text { severe post-ERCP pancreatitis } \\
1 \times \text { perforation secondary to stent in advanced malignancy } \\
1 \times \text { advanced malignancy deterioration post-failure to cannulate and PTC }\end{array}$ \\
\hline EUS & 2 & $\begin{array}{l}1 \times \text { perforation } \\
1 \times \text { post-fine needle aspiration sepsis and hepatic decompensation }\end{array}$ \\
\hline OGD & 1 & Refractory bleeding post-biopsy (coincident disseminated intravascular coagulation) \\
\hline IGB & 1 & $1 \times$ perforation \\
\hline
\end{tabular}

that there are unavoidable factors, undergo review in morbidity and mortality meetings only.

In summary, the levels of investigation used were:

1. Local review by the endoscopy lead with presentation of findings in a bimonthly EUG meeting attended by all endoscopists and nurses.

2. Mini-RCA investigation tool

3. Hospital-level RCA

During this period, SJRs were established nationally for use after death in selected cases. SJR was adopted in two endoscopyrelated deaths.

\section{Results}

\section{Overview of incidents}

From July 2016 to February 2020 a total 63,006 procedures were performed. There were 73 reported cases of significant harm. Of these, 11 resulted in death.

Of the 11 deaths, seven were related to ERCP, two to endoscopic ultrasound (EUS), one to diagnostic esophageal-gastroduodenoscopy (OGD), and one to intragastric balloon insertion for treatment of obesity. Details are presented in $>$ Table 1.

Overall, 30 PSIs were related to hepatobiliary (HPB) endoscopy, 17 to lower gastrointestinal (LGI) endoscopy, and 26 to upper gastrointestinal (UGI) endoscopy. Specific complications are described in $>$ Table 2 .

Permanent injury occurred in two cases, including a stoma formation and a hemiparesis secondary to cerebral thromboembolism in the context of anticoagulant cessation.

Median length of stay in the 68 patients admitted to our hospital was 6 days, with range from 2 to 82 days.

\section{Level of investigation}

A hospital-level RCA was performed in six cases (4 deaths), a mini-RCA in 12 cases (4 deaths), a SJR in two cases (2 deaths), and 53 were examined by the endoscopy lead and presented in the bimonthly EUG meeting (1 death). Hospital-level RCAs were reviewed centrally and, in selected cases, the investigators were asked to present a summary to the Serious Incident Assurance Panel (SIAP), a multidisciplinary committee that reviews learning themes across the whole organisation and is attended by senior staff, the medical director, and a patient representative.

Four mini-RCAs were related to colonoscopies, one to enteroscopy, and seven to ERCP. Harm was judged to be moderate in seven cases and severe in five (including 4 deaths). All miniRCAs were completed within 28 days and reviewed in a monthly patient safety meeting with senior clinical and nursing staff before dissemination to the wider team.

\section{Learning themes}

\section{Mini-RCA}

No concerns were raised about patient fitness for procedure, WHO checklist observance, endoscopist KPIs, or immediate post-PSI management. Adequate MDT discussion was documented in cases where the patient was frail or had advanced malignancy. The WHO checklist had been completed and signed off in all cases and there was no incident in which a poor checklist practice was identified as a contributing factor. There were several instances of excellent practice following recognition of harm (e.g. immediate resuscitation, clear communication with families, rapid escalation).

Regarding wider lessons, the mini-RCAs contained rich educational material ( $>$ Table 3 ).

No clearly avoidable factors were identified in the hospitallevel RCAs. One incident was related to a novel esophageal ablation device, which was consequently discontinued. Another highlighted the need to consider and confirm the appropriateness of cardiopulmonary resuscitation prior to therapeutic procedures in critically unwell patients (following an intra-procedural cardiac arrest during ERCP for severe cholangitis with advanced malignancy). Another hospital-level RCA made a recommendation to establish regular human factors training for staff.

Dominant themes derived from mini-RCAs related to availability of equipment, the informed consent process (in particul- 
- Table2 Complications according to procedure type

\begin{tabular}{|c|c|c|c|}
\hline Procedure type & Complication & Number & Notes \\
\hline \multicolumn{4}{|c|}{ Lower gastrointestinal endoscopy $(n=17)$} \\
\hline \multirow[t]{3}{*}{ - Polypectomy (EMR) } & Bleed & 7 & \\
\hline & Perforation & 2 & \\
\hline & Stroke & 2 & Interruption to antiplatelet \\
\hline \multirow[t]{2}{*}{ - Diagnostic } & Perforation & 5 & 1 ileoscopy \\
\hline & $\mathrm{MI}$ & 1 & \\
\hline \multicolumn{4}{|c|}{ Upper gastrointestinal endoscopy $(\mathrm{N}=26)$} \\
\hline \multirow[t]{2}{*}{ - Diagnostic } & Aspiration & 1 & Under GA \\
\hline & Bleed & 3 & After biopsies \\
\hline - Variceal banding & Bleed & 1 & Uncontrolled, tamponade required \\
\hline \multirow[t]{2}{*}{ - Esophageal EMR } & Bleed & 1 & \\
\hline & Perforation & 1 & \\
\hline - Esophageal cryoablation & Perforation & 1 & \\
\hline \multirow{2}{*}{ - PEG insertion } & Site infection & 1 & \\
\hline & Bleed & 1 & \\
\hline \multirow{2}{*}{ - Intragastric balloon insertion } & Intolerance requiring admission & 11 & Balloon removed in all cases \\
\hline & Perforation & 1 & \\
\hline - Duodenal dilatation & Perforation & 1 & \\
\hline - Duodenal EMR & Bleed & 1 & \\
\hline \multirow{2}{*}{ - Endoscopic ultrasound } & Sepsis post-FNA & 1 & \\
\hline & Esophageal perforation & 1 & \\
\hline \multicolumn{4}{|l|}{ Hepatobiliary endoscopy $(\mathrm{n}=30)$} \\
\hline \multirow[t]{7}{*}{ - ERCP } & Perforation & 7 & \\
\hline & Pancreatitis & 12 & \\
\hline & Cholangitis & 3 & \\
\hline & Bleed & 3 & \\
\hline & Intra-procedural arrest & 2 & $\begin{array}{l}1 \times \text { from intensive care, intubated/ventilated and on } \\
\text { vasopressors } \\
1 \times \text { frail metastatic pancreatic cancer }\end{array}$ \\
\hline & Intra-procedural AF & 1 & \\
\hline & Hepatic decompensation & 1 & \\
\hline - Ampullectomy & Pancreatitis & 1 & \\
\hline
\end{tabular}

ar, inadequate detail regarding risks on the consent form and lack of clarity around mental capacity to give informed consent), communication within the room, and technical considerations. No concerns were raised regarding competence, training, supervision, or immediate medical management. In several cases the investigator highlighted excellent care, and this was fed back to those involved and allowed positive dissemination and reinforcement of good clinical practice.
Regarding equipment, the importance of having the most appropriate items readily available (e. g. selection of stents, pediatric colonoscope) was emphasized, and departmental changes were made accordingly. One case identified the risks related to staff swapping into and out of complex procedures, such that the new staff member was not familiar with the current stage of the procedure, affecting the quality of communication and team synchronization. In several cases, the investi- 
- Table 3 Learning summaries from 12 mini-RCAs

\begin{tabular}{|c|c|c|c|c|}
\hline Procedure & Complication & Consequence & $\begin{array}{l}\text { Harm } \\
\text { grading }\end{array}$ & Learning points \\
\hline $\begin{array}{l}\text { Lower gastro- } \\
\text { intestinal }\end{array}$ & Perforation & $\begin{array}{l}\text { Hartmann's procedure } \\
\text { and reversal }\end{array}$ & Severe & No specific learning \\
\hline $\begin{array}{l}\text { Lower gastro- } \\
\text { intestinal }\end{array}$ & Perforation & $\begin{array}{l}\text { Conservative manage- } \\
\text { ment, } 5 \text { days }\end{array}$ & Moderate & $\begin{array}{l}\text { Question indication for colonoscopy if doubtful } \\
\text { (discuss with referer) }\end{array}$ \\
\hline ERCP & $\begin{array}{l}\text { Jejunal perforation (Bill- } \\
\text { roth II anatomy) }\end{array}$ & $\begin{array}{l}\text { Surgical resection of new } \\
\text { cancer and reconstruction }\end{array}$ & Moderate & $\begin{array}{l}\text { Ensure contemporaneous scans available. Em- } \\
\text { phasize increased perforation risk at consent }\end{array}$ \\
\hline ERCP & $\begin{array}{l}\text { Pancreatic duct perfora- } \\
\text { tion and pancreatitis }\end{array}$ & $\begin{array}{l}\text { Prolonged and recurrent } \\
\text { admissions }\end{array}$ & Moderate & $\begin{array}{l}\text { Ensure full suite of stents in stock. Achieve } \\
\text { "looped-back" wire position in pancreatic duct }\end{array}$ \\
\hline ERCP & $\begin{array}{l}\text { Bile duct perforation by } \\
\text { trawling balloon }\end{array}$ & Repeat ERCP, full recovery & Moderate & $\begin{array}{l}\text { Nurse- doctor communication training; change } \\
\text { rules around staff swapping during procedure }\end{array}$ \\
\hline Enteroscopy & Perforation & Resection & Moderate & Ensure enteroscope/pediatric c-scope available \\
\hline ERCP & $\begin{array}{l}\text { Post-sphincterotomy } \\
\text { bleed }\end{array}$ & $\begin{array}{l}\text { ICU admission, delay to } \\
\text { cancer therapy }\end{array}$ & & $\begin{array}{l}\text { Reflect on choice of therapy in Jehovah's Wit- } \\
\text { ness patients; create post-ERCP alert sheet for } \\
\text { referring teams }\end{array}$ \\
\hline ERCP & $\begin{array}{l}\text { Duodenal perforation by } \\
\text { plastic biliary stent }\end{array}$ & Surgery & Moderate & $\begin{array}{l}\text { Review imaging from referral centers in MDT } \\
\text { prior to procedure. Consider stents with duo- } \\
\text { denal curve }\end{array}$ \\
\hline $\begin{array}{l}\text { Lower gastro- } \\
\text { intestinal }\end{array}$ & Perforation & $\begin{array}{l}\text { ICU admission, Hart- } \\
\text { mann's procedure }\end{array}$ & Severe & $\begin{array}{l}\text { No specific learning; consider individualized } \\
\text { consent process for GA patients }\end{array}$ \\
\hline $\begin{array}{l}\text { Lower gastro- } \\
\text { intestinal }\end{array}$ & Post-polypectomy bleed & $\begin{array}{l}\text { ICU admission, prolonged } \\
\text { stay }\end{array}$ & Severe & $\begin{array}{l}\text { Formalize and document output from polyp } \\
\text { MDT; individualized consent form in hgih-risk } \\
\text { cases }\end{array}$ \\
\hline ERCP & $\begin{array}{l}\text { Duodenal perforation by } \\
\text { plastic biliary stent }\end{array}$ & Laparotomy, repair & Severe & Consider use of stents with duodenal curve \\
\hline ERCP & Pancreatitis & Death & Severe & No improvements in care or specific learning \\
\hline
\end{tabular}

gator was concerned that the risk profile of the procedure was inherently high (e. g. ERCP via intubation of afferent loop following Billroth II surgery, colonoscopy under general anesthesia following previous difficulties), and suggested that consent forms should be clearly individualized to describe higher than usual perforation rates in these cases.

Other learning points included the need for improved awareness about clinical features of concern after ERCP if patients are returned to a non-specialist ward (e. g. melena, pain) and the need to review the images of tertiary referrals carefully before proceeding (a case of unrecognized advanced malignancy). Finally, the need to consider contemporaneous imaging was raised after a complication in a patient whose bile duct stone had probably passed before ERCP.

\section{Hospital-Level RCA}

Following the death of a critically ill, intubated, and ventilated patient with advanced malignancy during ERCP, processes were changed to ensure the resuscitation status was agreed upon before entering the room. A death following gastric perforation from IGB insertion led to a new post-procedural pathway that involved an experienced nurse calling patients after IGB inser- tion to detect significant intolerance at an early stage. A pattern of readmissions due to balloon intolerance, sometimes leading to renal impairment and emergent endoscopic removal (not investigated by mini-RCA), fed into this pathway revision. The other four RCAs (perforation at EUS, bleeding after multiple gastric biopsies due to developing coagulopathy, esophageal perforation during cryoablation, sigmoid perforation during colonoscopy) did not identify learning points that required specific actions.

\section{Dissemination strategies and sustained learning}

All completed investigations were shared in the bimonthly EUG meeting and/or in monthly clinical meetings to discuss morbidity and mortality. Themes were also presented to endoscopy nurses in separate meetings, especially regarding ERCP and its inherent risks. An illustrated fact sheet about post-ERCP complications was written and circulated to the main referring teams within the Trust. New rules regarding swapping into and out of procedures were applied and responsibilities around ensuring the availability of equipment were clarified. Educational sessions regarding informed consent were organized. There is ongoing work around communication and human factors train- 
ing. Some investigations resulted in personal learning and reflection for individual endoscopists, usually relating to patient selection, choice of therapeutic modality, and approach to informed consent.

\section{Open communication with patients and relatives (duty of candor)}

A significant benefit of formal investigation by hospital-level RCA or mini-RCA was the opportunity to discuss the complication with the endoscopists and explore their concerns, especially around the DoC process, which included the requirement for a written apology to be sent to patients or relatives (if deceased). DoC was observed by involved clinicians in most cases, although trainees were supported either in person or via briefing and debriefing. DoC letters were written by the same person, except in cases in which significant time had elapsed (following hospital-RCA) in which case, the governance lead clinician wrote to ensure no further delays. Although openness about events causing significant harm and formal documentation had been a legal requirement in the UK since 2014, there remains variability in the extent to which this duty is discharged. During the period described here, expectations around $\mathrm{DoC}$ were clarified in all cases and the investigator was able to advise on and support the appropriate next steps.

\section{Discussion}

Errors and incidents in medical and surgical practice are frequent and are increasingly becoming a subject of public scrutiny and media attention, thus generating anxiety and undermining trust in both patients and healthcare personnel. Other highrisk industries have paved the way for positive management of incidents and near misses through which proactive reporting is encouraged by implementation of a culture that avoids personal blame and promotes learning, analysis, and prevention.

Gastrointestinal endoscopy in particular carries intrinsic risks due to its invasive nature and the increasing implementation of complex therapeutic procedures. Despite the implementation of many tools to prevent PSIs, including national and local guidelines, modified WHO checklists, and accurate pre-procedure assessment, incidents and complications happen and have a significant psychological impact on patients and the endoscopy personnel.

Furthermore, complications from endoscopy are to some extent "expected" and are explained to patients during the consent process. This often leads to discussion as to whether a complication (e.g. post-ERCP pancreatitis) should be examined at all. Although efforts have been made to standardize the grading of harm related to endoscopy, this remains a subjective process in most centers [8]. This is an additional argument for investigating complications swiftly and outside the usual RCA process unless there is a clear cause for concern.

The mini-RCA innovation was developed to fill the above gap between informal investigations and the hospital-level RCA. It was not designed as a clinical intervention, but to increase and streamline the number of investigations, thereby giving more opportunities for learning. It is not possible to show that a three-tiered approach reduces the frequency of patient safety incidents, as data from the previous era are not readily available and the available data do not lend themselves to statistical analysis. In the industrial and medical safety literature, the link between learning from incidents and risk reduction with improved patient safety remains unproven and is an "article of faith" [9]. Learning is relatively easy to "deliver," but demonstrating that it is embedded is harder. It is too early to demonstrate that the learning points and associated actions have been fully embedded, though open discussions, presentations, and focused training in the relevant areas took place. Positive departmental cultural changes (again difficult to quantify) occur after such interactions. Importantly, completed mini-RCAs are archived locally and serve as a store of learning that can be referred to and presented to incoming staff members.

\section{Limitations}

This report has specific limitations. It is from a single center. Although many PSIs were identified via proactive search and spontaneous, real-time reports, it is possible that some were missed. Because the reporting of PSIs relied partly on the endoscopists self-reporting immediate or delayed complications, there is a risk of reporting bias in this system, in particular, for near misses. However, this risk was greatly mitigated by the presence of multiple and independent reporting sources, including nurses, other teams via Datix, patient safety leads, and automated recording or unplanned admissions. There is subjectivity regarding the assessment of the degree of harm. In this unit's experience, this variability was minimized by using a small group of experienced clinicians to make those decisions and reaching consensus based on experience. However, there are no detailed indexes to determine what outcome leads to which specific degree of harm, as the individual impact on each patient may vary. Details of patients admitted to other hospitals with complications (mild or severe) may not have been forwarded to the department, although we are confident that the most significant incidents were communicated back and investigated. Investigation of incidents is often reliant on documentation rather than detailed testimony from involved parties. A completed document (e.g. the WHO checklist or consent form) does not guarantee that it was utilized correctly, with adequate sharing of information and discussion. This weakness is inherent in all clinical areas.

Finally, while the patient is the final arbiter of harm, clinicians were the ones who decided what grade of harm had been suffered and what level of investigation was required. This is the case in most areas, but a patient-centered approach would both request and consider account feedback while arrangements for investigation were under way.

\section{Future developments}

Ideally, validation of this three-tiered approach using a focused mini-RCA tool would occur in other units. The experience described here has resulted in an archive of learning, and there is the potential for sharing themes with other centers. JAG already promotes shared-learning initiatives, including the publication of a "case of the month" (indeed, one of the cases investigated 
here was featured), and one strategy would be to present the mini-RCA in that forum. To answer the question about validity, long-term monitoring of changes in processes and new PSIs will be undertaken to check that avoidable errors are not being repeated. In addition, a questionnaire-based study of nurse and clinician recollection and implementation of lessons learned would provide a stronger evidence base for improvement.

\section{Conclusions}

A three-tiered approach to PSIs in endoscopy allowed rapid investigation and appropriate actions to be taken. The novel miniRCA tool sits between informal investigation and formal hospital-level RCA, and in this unit's experience, has accelerated learning after significant harm events. It is complementary to the established RCA tool, which continues to be used in selected cases - usually where Trust-level learning is anticipated. Additional benefits were opportunities to ensure timely communication with patients and relatives, and to support colleagues through the process. The spectrum of PSIs described here is likely to represent those seen in any busy endoscopy unit and it is hoped that the learning points can be shared with other centers.

\section{Competing interests}

The authors declare that they have no conflict of interest.

\section{References}

[1] Peerally MF, Carr S, Waring J et al. The problem with root cause analysis. BMJ Quality Safety 2017; 26: 417-422

[2] Kingston M], Evans SM, Smith B] et al. Attitudes of doctors and nurses towards incident reporting: a qualitative analysis. Med J Aust 2004; 181: 36-39

[3] Royal College of Physicians, London. https://www.rcplondon.ac.uk/ guidelines-policy/mortality-toolkit-implementing-structured-judgement-reviews-improvement

[4] Berry PA. Doctor, patient and the duty of candour. BM] Blogs 9th October 2019. https://blogs.bmj.com/bmj/2019/10/09/philip-berrydoctor-patient-and-the-duty-of-candour/

[5] NHS Improvement. NRLS organisation patient safety incident reports: commentary 2019 12/12/19. https://improvement.nhs.uk/documents/5992/OPSIR_commentary_Sept_2019_FINAL.pdf

[6] Matharoo M, Haycock A, Sevdalis N et al. A prospective study of patient safety incidents in gastrointestinal endoscopy. Endosc Int Open 2017; 5: E83-E89

[7] Pham JC, Hoffman C, Popescu I et al. A tool for the concise analysis of patient safety incidents. Joint Commission J Quality Patient Safety 2016; 42: 26-AP3

[8] Cotton PB, Eisen GM, Aabakken L et al. A lexicon for endoscopic adverse events: report of an ASGE workshop. Gastrointest Endosc 2010; 71: 446-454

[9] Dekker S. Just culture: restoring trust and accountability in your organization. Boca Raton: FL: CRC Press; 2017 